\title{
La estructura de la intervención en el delito*
}

\section{The structure of the participation in the crime}

\author{
Prof. Dr. Dr. h. c. mult. Ricardo Robles Planas \\ Universidad Pompeu Fabra, Barcelona \\ ricardo.robles@upf.edu
}

\section{Resumen}

En el presente trabajo se vuelve a incidir en el desarrollo de una teoría de la intervención en el delito parcialmente discrepante con respecto al tradicional abordaje de la cuestión por parte de la teoría dominante. La construcción aquí mantenida parte de la distinción entre los dos momentos fundamentales de la responsabilidad penal de todo interviniente: la fundamentación de la relevancia típica de su intervención y la valoración de la intensidad de su injusto en relación con el injusto del hecho común. En esta ocasión se pone especial énfasis en las cuestiones estructurales y de teoría de las normas.

Palabras clave: intervención en el delito, autoría, participación, accesoriedad, teoría de las normas

\begin{abstract}
The present paper insists again on the development of a theory of the intervention in the crime partially dissenting from the traditional and dominant among the academics. The construction here defended takes as the starting point the distinction between the two fundamental moments of any intervener criminal responsibility: the fundamentals of the criminal relevance of his intervention and the assessment of his wrong intensity in comparison with that of the common wrong. On this occasion, special emphasis is placed on structural issues and on the implications of the Norm-theory.
\end{abstract}

Keywords: criminal participation, norm-theory.

\footnotetext{
* La redacción del presente trabajo se enmarca en la ejecución del proyecto I+D DER2017-82232-P (AEI ; FEDER, UE). La versión alemana se publicó con el título "Die Struktur der Beteiligung" en HILGENDORF ; LERMAN ; CÓRDOBA (Eds.), Brücken bauen. Festschrift für Marcelo Sancinetti zum 70. Geburtstag, Duncker \& Humblot, 2020, pp. 617 y ss.
} 


\section{Introducción}

Según la concepción todavía hoy dominante, los tipos de la Parte Especial los realizan los autores. Esto es, los tipos darían respuesta simultáneamente a dos preguntas: la de cuál es el objeto de la imputación: el injusto típico; y la de a qué sujetos se les imputa ese objeto como propio: solo a los autores ${ }^{1}$. Los partícipes, en cambio, son punibles en virtud de las reglas de la Parte General que extienden la punibilidad a intervenciones accesorias. En este sentido, se afirma que mientras que la responsabilidad de los autores no es dependiente, la de los partícipes sí lo es: su castigo requiere un hecho realizado por un autor con unas determinadas características. Esta es la esencia del denominado concepto restrictivo de autor y de su complemento indispensable: el principio de accesoriedad de la participación. La accesoriedad cuantitativa se refiere al requisito de que el hecho principal (del autor) debe haber alcanzado como mínimo el estadio ejecutivo para poder castigar al partícipe. Solo excepcionalmente la ley prevé también el castigo de conductas de intervención no seguidas de ejecución como la proposición, la provocación o la conspiración. La accesoriedad cualitativa se refiere a qué características delictivas debe revestir el hecho principal (del autor) para poder castigar al partícipe. En la actualidad es dominante la accesoriedad limitada, que requiere de un hecho típico y antijurídico pero no culpable. Aunque por alguna razón decaiga la completa afirmación de la tipicidad y antijuridicidad del comportamiento del autor y, sin embargo, subsista el merecimiento de pena en la conducta del partícipe, no podrá castigársele. Así descritas, las dos dimensiones de la accesoriedad parecen tener un contenido limitador de la responsabilidad del partícipe.

Sin embargo, el problema de esta comprensión del fenómeno de la intervención en el delito reside en que deja huérfano de fundamento positivo al injusto del partícipe. Simplemente presupone que quien lleva a cabo un comportamiento accesorio (no típico) debe responder. Pero ¿por qué responde? Si el hecho típico, por muchas características que se exija que concurran en él, es el hecho del autor ¿no estamos ante responsabilidad por un hecho ajeno?. Para evitar esta conclusión Marcelo Sancinetti advierte acertadamente de la necesidad de fundamentación del injusto propio del interviniente ${ }^{2}$. Sin embargo, nuestros caminos pronto se separan. Él sostiene lo que yo he denominado un "sistema de responsabilidad por la propia infracción de la norma", un modelo dogmático que comparten los conceptos unitarios de autor, las teorías puras de la causación y la teoría del delito de infracción de un deber, caracterizado por prescindir por completo de la idea de accesoriedad y establecer como relevante únicamente la relación entre cada interviniente y su norma. Como se verá, un modelo así no es incorrecto per se, pero presupone que los tipos de la Parte Especial quieren sancionar toda infracción de la norma de conducta del interviniente, lo que, al menos en los delitos de organización (deberes negativos), no parece asumible. ${ }^{4}$ Por ello, la idea que late detrás de la accesoriedad es esencialmente correcta: la punibilidad de ciertas conductas de intervención depende de que se produzca una realización típica (se dé por lo menos inicio la

\footnotetext{
${ }^{1}$ Muy claro, OTTO (2017), pp. 21-26: "el concepto restrictivo de autor parte de la base de que la descripción del tipo penal constituye al mismo tiempo una descripción del autor". Véase también, RENZIKOWSKI (2014) pp. 47-68 y ss.

${ }^{2}$ SANCINETTI (1996) passim.

${ }^{3}$ ROBLES PLANAS (2003), p. 145.

${ }^{4}$ Véase en torno a la nota 23.
} 
tentativa). Lo que no es correcto es entender que esa realización sea propiedad del autor y, por consiguiente, algo ajeno para el partícipe. Esto implica una reconstrucción teórica que he propuesto denominar "sistema de responsabilidad por la intervención"5.

\section{Los dos niveles del sistema de responsabilidad por la intervención en el delito ${ }^{6}$}

Se trata de identificar las dos operaciones básicas en la determinación de la responsabilidad penal en casos de pluralidad de intervinientes: primero es necesario afirmar la presencia de una conducta típica de intervención en el delito. Después, una vez se ha constituido el círculo de sujetos responsables, debe graduarse la magnitud de cada una de las aportaciones.

La primera operación -la constitución de la intervención- es irrenunciable: solo puede responderse por haber llevado a cabo un comportamiento no permitido y, por tanto, es necesario averiguar si la conducta del sujeto tiene significado delictivo o se mueve en el ámbito de lo típicamente inocuo. En la actualidad está fuera de discusión que los criterios de la denominada "teoría de la imputación objetiva" son aplicables a todos los intervinientes (no solo a los tradicionalmente denominados "autores"), superando así cualquier vestigio de mera responsabilidad causal o basada en las intenciones. La teoría de las conductas neutrales ha dirigido convenientemente la discusión en los últimos años hacia el punto decisivo: existen espacios de intervención en el delito permitidos. Pero más allá de establecer los límites de la intervención punible (véase el apartado $\mathrm{N}^{\circ} 2$ ), esta primera operación -la integración del momento constitutivo de la intervención en el ámbito de la "imputación objetiva"- tiene implicaciones que revolucionan el planteamiento dominante hasta hacerlo irreconocible: el abandono del concepto de autor como punto de partida (véase el apartado $\mathrm{N}^{\circ} 3$ ) y una nueva comprensión de la estructura normativa de la intervención y de la problemática de la accesoriedad (véase el apartado $\mathrm{N}^{\circ} 4$ ).

La segunda operación también es irrenunciable. No resulta adecuado un sistema de intervención en el delito que renuncia a graduar la responsabilidad en virtud de la relevancia de las aportaciones de cada interviniente. Que ello es así, se expresa de modo claro en la inmensa mayoría de los códigos penales de nuestro entorno cultural. Ni tan siquiera en los denominados "sistemas unitarios de autor" se opera sin recurrir a graduaciones. En este punto es importante tener en cuenta que las decisiones básicas suelen reconducirse a dos: mantener el mismo marco típico para ciertas intervenciones de mayor importancia y establecer un marco penal atenuado para otras intervenciones de menos peso. Esto es lo que en el fondo sucede también en códigos penales como el español o el alemán, donde al final todo depende de si la calificación de la aportación implica la pena prevista en el tipo o una pena inferior (en cuyo caso estamos ante "cómplices"). En este punto se esperarán criterios claros de determinación del quantum de pena, pero tales criterios no pueden ser establecidos más que en sus rasgos fundamentales, exactamente lo mismo que sucede con las reglas generales de determinación de la pena (véase el apartado $\mathrm{N}^{\circ} 5$, donde, de paso, habrá de hacerse una crítica al pensamiento fenomenológico que ha ensombrecido la esencia del problema durante décadas).

\footnotetext{
${ }^{5}$ ROBLES PLANAS (2003), p. 145.

${ }^{6}$ Véase en lo que sigue, ROBLES PLANAS (2012a), pp. 1 y ss.; ROBLES PLANAS (2012b), pp. 276 y ss.), con ulteriores referencias.
} 


\section{2. ¿Cuándo hay intervención en un delito?}

Intervenir en un delito es aportar algo penalmente relevante al hecho injusto. "Penalmente relevante" significa de forma desaprobada por el Derecho penal, lo que implica que también hay formas "permitidas" de intervenir en un delito. A estas últimas también se las denomina "conductas neutrales" o casos de "prohibición de regreso"7. Normalmente se hallarán muchas conductas neutrales en las aportaciones previas al inicio de la ejecución, pues, en términos generales, uno no tiene que preocuparse de que otros sujetos autorresponsables no deriven posteriormente hacia lo delictivo las propias aportaciones. Rige, por tanto, un principio de separación de esferas, lo que es acorde con sociedades complejas con alto grado de división del trabajo en las que la interacción social se articula sobre la base de esferas de competencias delimitadas. Ahora bien, quedarse ahí sería tanto como quedarse con lo fenomenológico: también pueden ser neutrales las aportaciones prestadas con posterioridad a otras que ya están impregnadas de lo delictivo ${ }^{8}$. Es el conocido caso del estudiante de biología que trabaja como camarero y sirve una ensalada con frutos venenosos que ha preparado el cocinero, pero también el del operario que en una industria vierte al medio ambiente contenedores contaminados por decisión de los superiores. En ambos casos, a pesar de actuar en último lugar "permitiendo" la realización del tipo, el sujeto no es en absoluto garante de que no se realice, por lo que solo cabe, en su caso, un reproche conforme a deberes generales de omisión (art. 195 CP español, § 138 StGB).

Todo lo contrario sucede cuando el sujeto, actúe con anterioridad o posterioridad a otro sujeto, es garante de que no se produzca la realización del tipo. Ello sucede en casos de prestaciones en sí peligrosas sometidas a regulación especial por el Ordenamiento jurídico. No es necesario advertir que esto último es excepcional, por lo que la regla general se confirma: la intervención en un delito suele ser un riesgo permitido. Intervención penalmente relevante solo habrá, más allá de los mencionados casos poco frecuentes de posiciones de garantía especiales, allí donde se supere el amplio riesgo básico del que todos partimos en el interactuar social. Y ello no sucede a partir de causaciones, conocimientos o intenciones, sino a partir del significado objetivo de la conducta: si esta puede interpretarse objetivamente como parte del delito o como algo aún distanciado 9 . Una conducta forma parte de un delito cuando quien la lleva a cabo le ha dado la forma específica para que encaje en él. A este criterio de imputación, que es lo suficientemente amplio para englobar otros subcriterios, pero lo suficientemente estrecho para excluir un gran grupo de casos que aún hoy se tratan como intervención punible por un sector de la doctrina y la jurisprudencia, lo he denominado "conducta de adaptación". ${ }^{10}$

\section{3. ¿El concepto de autor como punto de partida?}

\footnotetext{
${ }^{7}$ Fundamental, sobre esto y en lo que sigue, JAKOBS (1977), pp. 409 y ss.; JAKOBS (2016) pp. 53 y ss. Véase, además, FRISCH (2002), pp. 539 y ss.; ROBLES PLANAS (2003), pp. 24 y ss. y 275 y ss.; ROBLES PLANAS (2008), pp. 18 y ss., con amplias referencias bibliográficas.

${ }^{8}$ Por cierto, quien prefiera la denominación "prohibición de regreso" o "de retroceso" tendría aquí que utilizar la expresión "prohibición de progreso" o "de avance".

${ }^{9}$ JAKOBS (2016), pp. 53 y ss.

${ }^{10}$ ROBLES PLANAS (2003), pp. 303 y ss.; ROBLES PLANAS (2008), p. 30, con referencias a los planteamientos de Jakobs y Frisch.
} 
1. Un sistema de intervención en dos niveles como el aquí esbozado -se dirá- no debe ser acogido porque opera exactamente al revés de como hay que operar. Primero hay que determinar la autoría y después la participación. El concepto de autoría es primario, el de participación secundario, derivado o accesorio. Con ello llegamos al más importante problema de la teoría tradicional: partir del carácter constitutivo de la figura del autor, el denominado concepto restrictivo de autor. En contra de lo afirmado por este planteamiento, aquí se entiende que los tipos de la Parte Especial no se refieren exclusivamente a la conducta de una clase de sujetos, los autores. Esto es, no definen el injusto punible $y$ a su vez a los que responden como autores del injusto punible. Si así fuera, el criterio de autoría (p. ej. el dominio del hecho), sería co-constitutivo del injusto. Los tipos dirían: "solo mata el que mata con dominio del hecho" o "solo es una muerte punible la producida con dominio del hecho" o, en fin, "sin dominio del hecho no hay delito de homicidio". Esto es absurdo ya porque el dominio del hecho tiene como referencia, precisamente, el acontecer típico, de manera que no puede a su vez ser parte del acontecer típico sin incurrir en un evidente vicio lógico. Más bien, los tipos de la Parte Especial contienen descripciones típicas "neutrales" 11 en cuanto a la ordenación de una u otra conducta dentro de las clásicas conductas de intervención en el delito ("autoría" y "participación"). Su formulación se agota en abarcar formas penalmente desaprobadas de intervenir en un delito (sea esta intervención constitutiva de "autoría" o "participación"). Como se ha afirmado, la determinación de cuándo estamos ante una conducta de intervención en el delito tiene lugar con arreglo a los criterios generales de la desaprobación de conductas. Por ello la clásica objeción dirigida desde el concepto restrictivo de autor y relativa a que desde otras perspectivas se estaría afirmando que "mata" quien simplemente dispone una condición causal, no rige para planteamientos que adoptan un concepto restrictivo de injusto ${ }^{12}$, esto es, un concepto no basado en la causalidad, sino normativo: mata todo aquel al que se le puede "imputar objetivamente" una muerte.

2. Aferrarse a una "figura central" es una petición de principio que desplaza a los demás intervinientes hacia el déficit de fundamentación de su responsabilidad. ¿Acaso no convendría comenzar por lo que une a "autores" y "partícipes" en lugar de hacerlo por lo que los separa? La teoría dominante opera, en primer lugar, identificando las propiedades de un determinado tipo de intervinientes, los "autores", para, en segundo lugar, construir la responsabilidad del otro tipo de intervinientes, los "partícipes", en conexión con aquellos. Este curioso proceder debería ceder el terreno a otro más lógico: primero, examinar lo que vincula a todos los intervinientes (la constitución de la responsabilidad conjunta por el hecho) para, después, analizar lo que los separa (el diferente peso de las aportaciones) ${ }^{13}$. Se insistirá por algunos en que entre "autores" y "partícipes" se da una diferencia cualitativa fundamental, a saber, que mientras a los "autores" se les puede imputar el hecho como propio a los "partícipes" solamente se les puede imputar el hecho como ajeno. Esta extendida afirmación merece ser desterrada. En un Derecho penal respetuoso con el principio de responsabilidad personal no es posible hacer responder a nadie por un injusto ajeno. En esa

\footnotetext{
${ }^{11}$ Acertadamente, ROTSCH (2009), p. 281.

${ }^{12} \operatorname{LESCH}$ (1992), p. 272.

${ }_{13}$ Así, ROBLES PLANAS (2003), pp. 219 y ss. y 261 y ss.; robles planas (2007), pp. 20 y ss.; ROBLES PLANAS (2012a), pp. 1 y ss.; ROBLES PLANAS (2012b), pp. 276 y ss. Últimamente también, OROZCO LÓPEZ (2018), pp. 196 y ss.
} 
medida es incorrecto entender que a los "partícipes" se les imputa un hecho ajeno. A ellos también se les (debe) imputa(r) el hecho como propio. Ahora bien, es cierto que un hecho no solo es propio cuando se ejecuta de propia mano (por uno mismo), sino que un hecho también es propio cuando otro lo lleva a cabo para mí, como está ampliamente reconocido por las figuras jurídicas del mandato y la representación ${ }^{14}$. En esa medida es incorrecto entender que solo a los "partícipes" se les imputa algo "ajeno": también en la coautoría se le imputa a cada coautor como propia una parte del hecho que no ha realizado de propia mano ${ }^{15}$. Con otras palabras, es cierto que tanto en la "(co)autoría" como en la "participación" se le imputa al interviniente una parte del hecho que no realiza de propia mano, pero ello no significa que se les esté imputando un hecho ajeno: no es ajeno en la medida en que el interviniente lleva a cabo una aportación cuyo significado es la de hacer (también) suyas el resto de aportaciones. La "magia" de la teoría de la intervención en el delito consiste, pues, en que permite asignar responsabilidad a un sujeto por acciones que no lleva a cabo personalmente pero que le son tan propias como las que sí lleva a cabo personalmente; estas últimas deben tener el significado precisamente de atraer para sí como normativamente propio lo que es naturalísticamente ajeno. He aquí, pues, el cometido del primer nivel del sistema de intervención en el delito: determinar qué aportaciones se engarzan en un mismo hecho, de manera que se les pueda atribuir a todas ellas ese hecho, aunque este no se haya ejecutado de propia mano.

\section{La estructura normativa de la intervención. Accesoriedad}

\subsection{Norma de conducta, norma de sanción, accesoriedad}

Según lo dicho, los preceptos de la Parte Especial están concebidos para los casos en los que actúa u omite un único agente ${ }^{16}$. En la medida en que aparecen otros sujetos que pueden ser igualmente responsables, la situación debe ser reconstruida: reconstruir la norma de sanción significa, ante todo, reconocer que lo que puede efectuar uno solo, puede también llevarse a cabo entre varios ${ }^{17}$.

Así, en la intervención en el delito, cada interviniente infringe su propia norma de conducta (deber). A la conducta de todos ellos subyace una valoración negativa común, que se concreta según los postulados de la "imputación objetiva". La norma de conducta prohíbe a cada interviniente realizar una aportación con significado delictivo. Ciertamente, la norma de sanción puede exigir para sancionar ciertos requisitos adicionales (véase infra, inmediatamente), pero ello no significa que aquellas conductas dejen de ser antinormativas ${ }^{18}$. Lo jurídico-penalmente sancionable es más reducido que lo antinormativo.

\footnotetext{
${ }^{14}$ Al respecto ya BINDING (1908), p. 8. Véase también, JAKOBS (2016), p. 32.

15 Expresamente, LESCH (1992), p. 274-275; ROBLES PLANAS (2003), p. 155; recientemente también, OROZCO LÓPEZ (2018), pp. 199 y ss.

${ }^{16}$ Así también, FREUND (2009) pp. 10-11.

${ }^{17}$ De otra opinión, FREUND (2009), pp. 10-13 y 10-16 y ss.

${ }^{18}$ Sobre la antijuridicidad de las aportaciones pre-ejecutivas, véase, acertadamente, PEÑARANDA RAMOS (1990), p. 328. A continuación expongo ideas embrionariamente anunciadas en ROBLES PLANAS (2012b), p. 278; ROBLES PLANAS (2012a) pp. 4-5; ROBLES PLANAS (2003), pp. 149-153. Ha desarrollado este planteamiento extensamente, Vacchelli, Intervención delictiva, passim, llegando a conclusiones ampliamente compartibles, si bien para él los preceptos que castigan la participación en la Parte General tienen carácter constitutivo para el caso de las intervenciones prestadas antes del inicio de la tentativa. Pero si así fuera, no
} 
En realidad, en el plano de la norma de conducta, la esencia de la intervención en el delito está en la coordinación objetiva de diversas aportaciones en aras a la realización delictiva. Por tanto, lo relevante es si cada aportación individual tiene el significado objetivo de ensamblarse con otras como proyecto delictivo común, o bien puede aislarse del resto. Para que suceda lo primero será necesario que la conducta esté especialmente recortada para la realización, junto con otras, del tipo. La accesoriedad en la norma de conducta no es otra cosa que este fenómeno (objetivo) de acoplamiento de conductas que implica poder prohibir una conducta precisamente porque tiene el sentido de incorporarse a un proyecto delictivo, esto es, formar parte, junto con otras, de la organización de un delito. Dicho con una imagen: la accesoriedad permite "rellenar" lo que a la conducta le falta para ser una configuración exclusiva del hecho. Que ello no es algo específico de la "participación", sino que alcanza también a la "coautoría" debería haber quedado claro de lo afirmado anteriormente. ${ }^{19}$

En el nivel de la norma de sanción las cosas son distintas. No toda infracción de una norma de conducta es, solo por ello, típica. Únicamente llegan a ser típicas aquellas conductas que infringen una norma $y$, por tanto, se hallan normativamente vinculadas a un mismo hecho cuando ese hecho posee unas determinadas propiedades: constituir un injusto típico. Y solo constituyen injustos típicos los hechos que alcanzan un nivel de lesividad determinado: allí donde se inicia la ejecución ${ }^{20}$. Cuando se inicia la ejecución todas las aportaciones normativamente vinculadas al hecho pasan a ser típicas. No solo es típica la conducta del ejecutor que da inicio a la realización del tipo, sino también las conductas de los sujetos que han obrado con anterioridad posibilitando la ejecución. De ahí que aquí se sostenga repetidamente que el tipo de la Parte Especial no solo comprende las conductas de "autoría", sino también las de toda intervención penalmente relevante, pues a todas ellas les es posible "imputar objetivamente" el injusto típico que se realiza. ${ }^{21}$

La ejecución es, por así decirlo, el "resultado" de la actuación coordinada de los diversos intervinientes. Unos y otros, con sus respectivas conductas antinormativas, habrán configurado, en mayor o menor medida, esa ejecución. Esto no solo es válido para el interviniente que realiza una contribución de menor importancia (y entonces se le denomina "cómplice"), sino también para el interviniente que configura la parte más importante del suceso (y entonces se le denomina "autor"). También en el caso de este último habrá que esperar a que las consecuencias de la infracción de la norma de conducta alcancen un determinado estadio para afirmar que se llega al ámbito de lo punible. El que la sanción de todos los comportamientos deba esperar al inicio de la ejecución no significa que deba

\footnotetext{
habría que dejar impunes las participaciones no seguidas de ejecución. Si ello es así es porque también la intervención prestada antes del inicio de la ejecución se somete a la lógica del tipo de la Parte Especial. Primera aclaración: una cosa es la infracción de la norma de conducta del interviniente y otra su sanción con pena. Del tipo también se derivan esas normas de conducta referidas a las aportaciones pre-ejecutivas, pero añade el requisito de que el hecho entre en estadio ejecutivo para poderlas castigar con pena. Segunda aclaración: con la entrega del arma no se empieza a realizar el tipo, sino solo con el inicio de la tentativa, pero es también inicio de la realización del tipo para el que entregó el arma.

${ }^{19}$ Véase nota 15.

${ }^{20}$ Acertadamente, JAKOBS (2016), p. 9 y passim.

${ }^{21}$ ROBLES PLANAS (2003), p. 137 y pp. 159-160.
} 
acogerse un concepto restrictivo de autor, sino únicamente de hecho o, si se quiere, de injusto punible $^{22}$.

Como puede observarse, con lo anterior se depura el significado de la accesoriedad (externa o cuantitativa) en un triple sentido: por un lado, se mantiene lo que de correcto hay en su núcleo, esto es, que toda aportación efectuada antes del inicio de la ejecución no es per se típicamente relevante; por el otro, se evita el adelantamiento de la punibilidad que implica la renuncia a toda accesoriedad como abiertamente reconocen los partidarios de esta última solución $^{23}$; y, finalmente, se supera la parcialmente acertada crítica de estos partidarios (los que renuncian a toda accesoriedad) relativa a que cada interviniente solo puede responder de su propio injusto y no de un injusto ajeno ${ }^{24}$ : sucede que el injusto del hecho es propio de todo interviniente aunque no se ejecute de propia mano y no pertenece solo a alguno de ellos (el último que decide, el ejecutor, el que lo domina, etc).

Lo anterior se refiere a la accesoriedad externa o cuantitativa. La pregunta por la accesoriedad interna o cualitativa es la relativa a qué elementos debe realizar cada interviniente personalmente y cuáles en cambio puede "tomar prestados" de las aportaciones de otros intervinientes. La respuesta, a la luz de las consideraciones anteriores, debería ser fácilmente deducible. Todo interviniente debe personalmente (¿cómo si no?) infringir una norma de conducta. En ello está presupuesta su culpabilidad. Ahora bien, no toda infracción de una norma de conducta resulta castigada por la norma de sanción. Los tipos de la Parte Especial recortan el ámbito de lo punible exigiendo requisitos adicionales. Pues bien, salvo en los delitos especiales de deber (Plichtdelikten), tales requisitos han de concurrir realmente para sancionar las infracciones de normas de conducta que objetivamente quedan vinculadas entre sí, pero como las aportaciones, precisamente, han quedado objetivamente vinculadas las unas con las otras (accesoriedad), solo es necesario que concurra el requisito típico adicional de alguna manera, no que cada sujeto lo realice personalmente. Con otras palabras: basta con que se aporte por parte de algún interviniente.

El planteamiento acabado de esbozar tiene muchas similitudes con el de Jakobs. En particular, es mérito de este autor haber puesto de manifiesto que la distinción más relevante en materia de intervención en el delito es la relativa a intervenciones pre-ejecutivas (preparación) e intervenciones ejecutivas (ejecución). El problema siempre estuvo en las intervenciones pre-ejecutivas, pues no se había logrado explicar convincentemente cómo un acto que se mueve en la fase de preparación y, por tanto, que no está prohibido si lo realiza el autor en solitario, pasa a estarlo cuando lo lleva a cabo otro. La respuesta que ofrece Jakobs es la siguiente: no está prohibido por la norma, sino que infringe únicamente una incumbencia $(\text { Obliegenheit })^{25}$. En cambio la respuesta que aquí se ofrece no requiere acudir a esa problemática noción: sí está prohibido por la norma que se dirige al interviniente, solo que

\footnotetext{
${ }^{22}$ LESCH (1992), p. 272.

${ }^{23}$ Por ejemplo, SANCINETTI (1996), p. 24. No obstante, la renuncia a la accesoriedad de este autor no es total: «en principio, prácticamente nunca debieran ser punibles la pura instigación o complicidad frustradas sin más. Porque la mera propuesta de cometer el hecho o de recibir el aporte difícilmente pudieran ocurrir al mismo tiempo en que ya hubiera oportunidades del nacimiento de una injerencia propia del autor principal».

${ }^{24}$ SANCINETTI (1996), passim.

25 JAKOBS (2016), p. 36.
} 
de no llegar a actualizarse en el inicio de la tentativa no será penalmente típico ${ }^{26}$. De nuevo: lo antinormativo es más amplio que lo típico. Esto requiere de alguna explicación adicional, pues en la base de la discrepancia hay, en efecto, una diversa concepción del término "norma". Para Jakobs norma y tipo coinciden ${ }^{27}$. Por ello afirma que solo la conducta de ejecución supone el quebrantamiento de una norma. "El injusto es solamente una conducta desde que se da comienzo a la realización del tipo hasta la ejecución de dicha realización (junto con la producción de resultados, cuando esta última sea eventualmente necesaria), lo cual significa que el injusto es solamente una conducta con el significado de un quebrantamiento de la norma, y no una conducta con el significado de que se está preparando un quebrantamiento de la norma que va a ocurrir en un momento posterior" 28 . Puede estarse de acuerdo en que el hecho injusto típico, punible, lo constituye aquello que por lo menos ha entrado en fase de tentativa. Antes de ello, en un Derecho penal del hecho, no hay nada salvo excepciones que requieren de una depurada legitimación ${ }^{29}$ - penalmente relevante. Ahora bien, la discrepancia reside en entender que la norma de conducta no pueda formularse ex ante e infringirse antes de que comience la ejecución. En efecto, Jakobs entiende la norma ex post como defraudación de expectativa penalmente respaldada. En cambio, aquí se parte -con Binding- de que de los tipos de la Parte Especial presuponen normas de conducta dirigidas a los ciudadanos y normas de sanción dirigidas a los órganos de Estado que tienen la misión de castigar la infracción de aquellas normas de conducta si se dan los requisitos adicionales que la ley penal eventualmente disponga. Pues bien, en la intervención en el delito un requisito de lesividad adicional general para poder castigar la infracción de la norma de cualquier interviniente es que se haya iniciado la tentativa, esto es, que el hecho sea típico.

\section{2. ¿Accesoriedad mínima, limitada o estricta?}

Un sistema de intervención en el delito pulveriza la vieja polémica -últimamente revividaen torno a si para poder castigar al partícipe, el hecho principal debe ser cometido por un autor que obre solo típicamente (accesoriedad mínima) o también antijurídicamente (accesoriedad limitada) o incluso culpablemente (accesoriedad máxima o estricta). En un sistema de intervención la discusión no tiene sentido porque la decisión fundamental gira entorno a la posibilidad de establecer un nexo de imputación entre interviniente e injusto, no entre interviniente y "autor" (al fin y al cabo otro interviniente). Ese nexo es de carácter objetivo-normativo y por eso la accesoriedad se refiere solo a la parte objetiva del injusto del hecho. La parte subjetiva es de cada interviniente: ni se comunica, ni se requiere para poder castigar a los demás. Naturalmente, si un interviniente obra sin culpabilidad, entonces no nace su responsabilidad. Pero eso no convierte en inocua la conducta del otro interviniente que sí obra culpablemente: su intervención es relevante y caso de que no hayan más intervinientes, será el único responsable y, por tanto, según la denominación legal, "autor". En realidad la polémica en este punto con Jakobs carece de sentido en la medida en que este autor no afirma, como a primera vista pudiera parecer en un partidario de la accesoriedad máxima o estricta, que no cabe castigar a quien interviene en un hecho de un inimputable,

\footnotetext{
${ }^{26}$ Véase nota 18.

27 JAKOBS (2016), p. 25-26 y p. 45.

${ }^{28}$ JAKOBS (2016), p. 31-32.

${ }^{29}$ En los actos preparatorios punibles lo que se adelanta no es la norma de conducta, sino la norma de sanción.
} 
sino que Jakobs castiga a ese interviniente considerando que es autor (mediato) ${ }^{30}$. La conclusión, por tanto, es idéntica a la que aquí se sostiene.

\section{Pena del "autor", pena del "cómplice". Fenomenología}

\subsection{Quantum de pena}

Un sector de la doctrina viene sosteniendo en los últimos años que la cuestión de la autoría y la participación debe resolverse con criterios cuantitativos ${ }^{31}$. En cambio, desde hace décadas la doctrina tradicional se ha venido empeñando en buscar un concepto de "autor". Esto en sí mismo no sería incorrecto si se redujera a afirmar que "autor" o "autores" son aquellos intervinientes que responden en mayor medida que otros, a los que hay que denominar "cómplices". Sin embargo, como ya se ha insistido antes, no es eso lo que se quiere decir tradicionalmente con la expresión "concepto de autor", sino que se quiere expresar que hay unos intervinientes "constitutivos" o "primarios" ("autores" en sentido estricto) y otros "derivados" o "accesorios" ("partícipes") 32 . Pero resulta que los "constitutivos" no lo son tanto porque, aunque responden en mayor medida, su responsabilidad también depende de los otros (en la coautoría) y los "derivados" tampoco lo son tanto porque, aunque dependen de los "constitutivos", el Derecho positivo les castiga tanto como a ellos (p. ej. la inducción). Esta situación ha ocultado lo que de razón tienen algunos "conceptos de autor" formulados en la doctrina. El concepto objetivo formal acierta en entender que normalmente la ejecución del delito es la aportación más relevante, por lo que la preparación acostumbrará a tener un papel de menor importancia. Pero no acierta al entender que solo el ejecutor es "autor" y que todo "autor" ha debido ejecutar (al menos algo). Todo hecho delictivo requiere de una ejecución, pero la ejecución no siempre es la parte más importante de un hecho delictivo. Es a consecuencia de su carácter formal, no de su carácter objetivo, que esta teoría debe ser abandonada. La teoría subjetiva acierta al entender que todos los intervinientes "quieren" el hecho, pero no cuando identifica a los autores como los que quieren el hecho como "propio" y a los partícipes como los que lo quieren como "ajeno". Todos los intervinientes quieren el hecho como propio, solo que a algunos de ellos se les puede responsabilizar más intensamente que a los otros porque lo han configurado más. Si se quiere seguir siendo un partidario de la teoría subjetiva simplemente habría que decir: todos han querido el hecho, pero unos lo han (¡lo habrán!) querido más que los otros porque lo han configurado (¡objetivamente!) más. La teoría del dominio del hecho acierta al distanciar formas de autoría (la mediata y la coautoría) de la ejecución de propia mano, esto es, da algún paso correcto en la línea de normativizar la valoración de las aportaciones. Pero su problema no es solo que la idea de dominio no se corresponda con la forma de atribuir socialmente responsabilidad preponderante o principal por un delito, sino que el dato del dominio no es lo decisivo para

\footnotetext{
30 JAKOBS (1996), pp. 268; JAKOBS (1997), pp. 562 y ss.; JAKOBS (2016), pp. 63 y ss. También, p. ej., PAWLIK (2012), p. 275 y s.; OROZCO LÓPEZ (2018), pp. 172 y ss.

${ }^{31}$ LESCH (1992), p. 195 y ss.; JAKOBS (2003), p. 570 y ss.; JAKOBS (2014), pp. 50 y ss. JAKOBS (2016), pp. 88 y ss.; ROBLES PLANAS (2012a), pp. 5 y ss.; ROBLES PLANAS (2012b), pp. 278 y ss.; CORNACCHIA (2007), p. 59; REYES ALVARADO (2007), pp. 567 y ss.; VAN WEEZEL (2006), pp. 60 y ss.; OROZCO LÓPEZ (2018), pp. 293 y ss.

${ }^{32}$ ROXIN (2017), p. 528.
} 


\section{Polít. Crim. Vol. 15, № 30 (Diciembre 2020), Art. 15, pp. 993 - 1007 [http://politcrim.com/wp-content/uploads/2020/12/Vol15N30A15.pdf]}

la responsabilidad: puede existir mucha responsabilidad con poco dominio y, al revés, mucho dominio y poca responsabilidad ${ }^{33}$.

Según lo afirmado, una aportación debe valorarse como de menor importancia, no cuando se da en el estadio pre-ejecutivo, sino cuando configura en menor medida el hecho. Un hecho puede venir altamente preconfigurado antes de la ejecución, especialmente cuando el interviniente ha definido decisivamente lo que vaya a suceder después. La "pena del cómplice" procede cuando su aportación (no permitida) supone (significa) una variación no relevante de "lo dado" o supone (significa) una fijación insuficiente de "lo que está por venir".

\section{2. ¿Autoría mediata?}

La denominada "autoría mediata" es la hija predilecta del pensamiento fenomenológico. Desde hace mucho tiempo se reconoce que alguien puede ser autor aunque sea otro quien ejecute un hecho: siempre que el segundo ejecute "para" el primero, donde "para" debe entenderse, modernamente, en el sentido de que al segundo no se le pueda imputar el hecho. En tal caso, hablar de autoría mediata no es del todo erróneo, pero confunde más que aclara: estamos en realidad ante una autoría "directa" 34 . Esto ya lo observó Binding, con su habitual agudeza: "ciertamente a este autor único se le denomina frecuentemente autor mediato, aunque esta es una mala expresión porque el autor mediato presupone lógicamente a un autor inmediato y sin embargo el instrumento humano incapaz de imputación no es idóneo para la autoría" 35 .

Que el Código penal alemán utilice para definir la autoría directa la expresión "cometa por uno mismo" es la razón que explica la pervivencia de la autonomía de la autoría mediata, pues en tales casos resulta difícil -aunque no imposible- afirmar que el autor de detrás comete "por sí mismo". En el Código penal español las cosas podrían ser más sencillas puesto que no se habla de comisión "por sí mismo", sino de realización del hecho "por sí solo".

Gran parte de los supuestos que se discuten en la doctrina sobre "autoría mediata" no son, en realidad, de "autoría mediata", sino de "un-interviniente-tras-otro-interviniente" (ergo: casos de intervención). En efecto, en todos aquellos casos en los que tanto la persona de delante como la de detrás llevan a cabo conductas no permitidas, ambas deben ser consideradas penalmente responsables y, por tanto, aquí el problema se -sit venia verbo- "reduce" a fundamentar la "autoría" del de atrás existiendo otro sujeto responsable, esto es, un problema de cuantificación de las aportaciones.

\footnotetext{
${ }^{33}$ ROBLES PLANAS (2012a), p. 6. Sobre ello, JAKOBS (2000), pp. 165 y ss.

${ }^{34}$ Así JAKOBS (2016), p. 68: "precisamente no es un caso de intervención, sino un caso de comisión directa fenotípicamente enmascarado" y p. 69.

${ }^{35}$ BINDING (1908), p. 5. Y en la p. 10 afirmando que en los delitos únicamente dolosos si el instrumento obra imprudentemente es como si fuera un inimputable, esto es, se trata al autor como autor único pese a que no haya ejecutado nada de propia mano. Si ello es así -añado yo- en los casos en los que el de delante obra imprudentemente ¿cómo no va a ser autoría única en los casos en los que el de delante ni tan solo obra imprudentemente? (p. ej. en error de tipo invencible -véase a continuación el texto-).
} 
Para la "autoría mediata" restarían aquellos casos en los que la persona de delante obra en error invencible. Ahora bien, si, como aquí, se entiende que el error invencible implica que la conducta no pueda ser objetivamente desaprobada (en terminología al uso: excluye la imputación objetiva), entonces, de nuevo, estamos ante un caso de autoría directa no ejecutiva.

Hay, por cierto, autoría directa no ejecutiva cuando un administrador ordena a un subordinado que lleve a cabo un comportamiento delictivo respecto del cual el subordinado no es garante ni tampoco adapta su conducta a lo delictivo (es, por tanto, neutral). ${ }^{36}$ Esto no debería escandalizar a nadie: cuando la persona de delante obra en ausencia de acción se entiende que el de detrás es autor directo. ${ }^{37}$ ¿Dónde está la diferencia en el plano normativo $^{38}$ ?

\subsection{Coautoría y complicidad}

La teoría del dominio del hecho llega a resultados plausibles en el tratamiento de la autoría mediata y la inducción porque en la primera puede admitirse con poco esfuerzo el dominio del de detrás ante la actuación como instrumento del de delante. Otra cosa sucede en los casos límite como el de los aparatos organizados, donde predicar el dominio del de detrás comienza a ser algo más que una metáfora, pero a consecuencia de la identidad penológica con la inducción la ordenación fenomenológica no acarrea mayor drama. En los supuestos de instrumento doloso no cualificado, en cambio, la calificación sí es decisiva y por ello la teoría del dominio del hecho es "retirada" de estos casos y sustituida por un criterio normativo de autoría, que se afirma extraer de la propia interpretación de algunos tipos de la Parte Especial (que se conciben como "delitos de infracción de un deber").

Con todo, la teoría del dominio del hecho fracasa estrepitosamente allí donde la afirmación del dominio requiere de una gran ficción normativa: en la coautoría. En ella, la producción del hecho requiere de la continuación responsable de las aportaciones por lo que no hay verdadero dominio de nadie sobre el conjunto. Lo que otorga la característica de autor, por oposición a la de cómplice, solo puede ser la importancia de la aportación. Esta objeción no la pueden superar tampoco quienes se aferran a que la aportación de un coautor debe darse en el estadio ejecutivo - para salvar la presencia de un "cierto" dominio del hecho- y entonces convierten en cómplice a quien realiza las aportaciones más importantes en fase de preparación, lo que en el StGB es dramático pero en el CP español no debido a la equiparación penológica entre cooperación necesaria y coautoría. En realidad, sin saberlo, el legislador español acierta en la perspectiva: no siendo relevante la distinción cualitativa entre coautoría y complicidad, lo que que importa es si a una aportación, por su importancia o esencialidad, le corresponde la pena prevista en el tipo de la Parte Especial (se llame como se llame la figura fenomenológica) o una pena atenuada ("cómplice"). Ello puede suceder tanto si la aportación se da en fase preparatoria, como en fase ejecutiva.

\section{4. ¿Autor detrás del autor?}

\footnotetext{
${ }^{36}$ Así también, BOLEA BARDON (2014), pp. 173 y ss.

${ }^{37}$ Así, ROXIN (2017), p. 703.

${ }^{38}$ Acertadamente, JAKOBS (1991), pp. 20-38.
} 


\section{Polít. Crim. Vol. 15, № 30 (Diciembre 2020), Art. 15, pp. 993 - 1007 [http://politcrim.com/wp-content/uploads/2020/12/Vol15N30A15.pdf]}

Esta construcción en sí no es errónea pero ni la denominación es del todo afortunada ni la figura es necesaria. Aquí no se trata de nada distinto al caso normal de la intervención en un delito. En el conocido caso Dohna hay primero que constituir la intervención y esta tiene lugar porque el delito se produce por la actuación coordinada de dos sujetos autorresponsables cuyos comportamientos están claramente desaprobados. En particular, llevar a la víctima B hasta un ejecutor responsable dispuesto a disparar, aunque solo lo estuviera respecto de la víctima A, a quien cree identificar correctamente cuando, en realidad, era B, constituye una conducta de intervención. No hay, pues, "autoría mediata". Ahora bien ¿cómo hay que calificar las aportaciones? Si se llega a afirmar que tan importante es la actuación del de detrás como la del delante, esto es, si se ve a ambos como "autores", entonces fenomenológicamente estamos ante un caso de "coautoría", por lo que, cabe insistir, la autonomía del concepto "autor tras el autor" pierde sentido.

Tampoco en los casos de aparatos de poder es necesario acudir a esta figura ${ }^{39}$ : son supuestos de intervención en el delito, donde tanto el superior como el ejecutor llevan a cabo comportamientos desaprobados de similar importancia y de un modo objetivamente coordinado: autoría de ambos; para los amantes de la fenomenología: "(co)autoría (vertical)". 40

\footnotetext{
${ }^{39} \mathrm{Al}$ respecto, OROZCO LÓPEZ (2018), pp. 348 y ss. con ulteriores referencias.

${ }^{40}$ De acuerdo, p. ej., BOLEA BARDON (2014), pp. 171 y ss.
} 


\section{Bibliografía citada}

BINDING, Karl (1908): “Die drei Subjekte strafrechtliche Verantwortlichkeit”, en: Der Gerichtssaal 71, pp. 1-21.

BOLEA BARDON, Carolina (2014): "Poder de mando y autor tras el autor", en: GIMBERNAT ORDEIG, Enrique; GRACIA MARTÍN, Luis; PEÑARANDA RAMOS, Enrique; RUEDA MARTÍN, Maria Ángeles; SUÁREZ GONZÁLEZ, Carlos; URQUIZO OLAECHEA, José (Eds.), Dogmática del Derecho penal. Homenaje a Bernd Schünemann por su $70^{\circ}$ aniversario, Tomo I (Lima, Gaceta jurídica), pp. 157177.

CORNACCHIA, Luigi (2007): "Fahrlässige Mitverantwortung”, en: PAWLIK, Michael ; ZACZYK, Reiner (Eds.), Festschrift für Günther Jakobs, (Berlin, Duncker \& Homblot), pp. 5577.

FREUND, Georg (2009): Strafrecht. Allgemeiner Teil, $2^{\mathrm{a}}$ ed., (Berlin ; Heidelberg ; New York, Springer).

FRISCH, Wolfgang (2002): "Beihilfe durch neutrale Handlungen. Bemerkungen zum Strafgrund (der Unrechtskonstitution) der Beihilfe", en: PRITTWITZ, Cornelius (Ed.), Festschrift für Klaus Lüderssen, (Baden-Baden, Nomos), pp. 539-557.

JAKOBS, Günther (1977): “Regreßverbot beim Begehungsdelikt”, ZStW 89 (1977), pp. 140.

JAKOBS, Günther (1991): Strafrecht. Allgemeiner Teil, 2a ed. (Belin ; NewYork, De Gruyter), 1991.

JAKOBS, Günther (1996): “Akzessorietät”, GA 1996, pp. 253-268.

JAKOBS, Günther (1997): “Objektive Zurechnung bei mittelbarer Täterschaft durch ein vorsatzloses Werkzeug”, GA 1997, pp. 553-572.

JAKOBS, Günther (2000): "Tatherschaftsdämmerung. Ein Beitrag zur Normativierung rechtlicher Begriffe", en: JAKOBS, Günther; CANCIO MELIÁ, Manuel, El sistema funcionalista del Derecho penal, (Lima, Grijley), pp. 195-225.

JAKOBS, Günther (2003): "Beteiligung”, en: DÖLLING, Dietrich (Ed.), Festschrift für Ernst-Joachim Lampe, (Berlín, Duncker \& Humblot), pp. 561-575.

JAKOBS, Günther (2014): Theorie der Beteiligung (Tübingen, Moher Siebeck).

JAKOBS, Günther (2016): Teoría de la intervención (Bogotá, Universidad del Externado).

LESCH, Heiko (1992): Das Problem der sukzessiven Beihilfe (Frankfurt a.M., Peter Lang).

OROZCO LÓPEZ, Hernán Darío (2018): Beteiligung am organisatorischen Machtapparaten, (Tübingen, Mohr Siebeck).

OTTO, Harro (2017): Manual de Derecho penal, $7^{\mathrm{a}}$ ed. (Barcelona, Atelier).

PAWLIK, Michael (2012): Das Unrecht des Bürgers (Tübingen, Mohr Siebeck).

PEÑARANDA RAMOS, Enrique (1990): La participación en el delito y el principio de accesoriedad (Madrid, Tecnos).

RENZIKOWSKI, Joachim (2014): en: MAURACH, Reinhart ; GÖSSEL, Karl-Heinz ; ZIPF, Heinz, Strafrecht. Allgemeiner Teil, $8^{\mathrm{a}}$ ed. (Heidelberg, C. F. Müller).

REYES ALVARADO, Yesid (2007): "Strafbare Beteiligung und objektive Zurechnung", en: PAWLIK, Michel ; ZACZYK, Reiner (Eds.), Festschrift für Günther Jakobs (Berlin, Duncker \& Humblot), pp. 553-570.

ROBLES PLANAS, Ricardo (2003): La participación en el delito: fundamento y límites (Madrid, Marcial Pons). 
ROBLES PLANAS, Ricardo (2007): Garantes y cómplices. La participación por omisión y en los delitos especiales(Barcelona, Atelier).

ROBLES PLANAS, Ricardo (2008): "Zwischen Beihilfe zur Tat und unterlassener Hilfeleistung. Zugleich ein Beitrag über die Verletzung der Solidaritätspflichten im Strafrecht", GA 2008, pp. 18 -32.

ROBLES PLANAS, Ricardo (2012): "Los dos niveles del sistema de intervención en el delito", InDret Penal $2 ; 2012$, pp. 1-26.

ROBLES PLANAS, Ricardo (2012): "Die Zwei Stufen der Beteligungslehre - am Beispiel der Beteligung durch Unterlassen”, GA 2012, pp. 276-290.

ROTSCH, Thomas (2009): "Einheitstäterschaft" statt Tatherrschaft (Tübingen, Mohr Siebeck).

ROXIN, Claus (2017): Täterschaft und Tatherrschaft, 9ª ed. (Berlin ; New York, Walter de Gruyter).

SANCINETTI, Marcelo (1996), El ilícito propio de participar en el hecho ajeno (Bogotá, Universidad del Externado).

VACCHELLI, Ezequiel (2018): Intervención delictiva: significado y función del principio de accesoriedad, tesis doctoral inédita, .

VAN WEEZEL, Alex (2006): Beteiligung bei Fahrlässigkeit. Ein Beitrag zur Verhaltenszurechnung bei gemeinsamem Handeln (Berlin, Ducker \& Humblot). 